\title{
Notas sobre os usos contemporâneos do peiote
}

\author{
Isabel Santana de Rose' \\ - Universidade Federail de Minas Gerais | Belo Horizonte, Minas Gerais, Brasil \\ $\checkmark$ belderose@gmail.com
}

LABATE, Beatriz Caiuby e CAVNAR, Clancy (eds.). Peyote: History, Tradition, Politics and Conservation. Santa Barbara/Denver, Praeger, 2016,312p.
O livro consiste em uma coletânea interdisciplinar que tem como eixo central o cacto peiote, Lophophora williamsii, popularmente conhecido por suas propriedades psicoativas e pela presença da mescalina, o principal princípio ativo da planta, que foi identificado pela primeira vez pelo farmacologista alemão
1 Pós-doutoranda no PPCAN/ UFMG. Este texto foi originalmente escrito para ser apresentado na I Jornada Plantas Sagradas em Perspectiva, realizada na Unicamp em agosto de 2016. Este trabalho contou com o apoio do CNPq via bolsa PDJ.

Arthur Heffter, em 1898. Com 12 capítulos e trazendo contribuições de diferentes áreas, como biologia, ecologia, história, direito, antropologia e ciências da religião, bem como a perspectiva indígena a respeito do tema, a coletânea aponta, ao mesmo tempo, diferentes visões e abordagens sobre o peiote e alguns temas e questões comuns ou transversais.

É difícil estimar precisamente há quanto tempo esse cacto vem sendo empregado por povos indígenas mexicanos, como Wixitari ou Huichol, Naayeri ou Cora e Raramuri ou Tarahumara, entre outros ${ }^{2}$, porém existem indícios de que seu uso, ligado a suas propriedades visionárias e terapêuticas, data de pelo menos cerca de dois mil anos antes da chegada dos europeus na América (Rojas-Arechiga e Flores 2016: 27). O peiote foi popularizado a partir dos anos 1960, impulsionado pelo movimento contracultural dessa época, no qual este cacto desempenhou um papel icônico (Labate, Canvar e Dawson 2016: XVII). Contribuíram para essa popularização um interesse crescente por plantas de poder e estados alterados de consciência, a publicação de livros como The doors of perception, de Aldous Huxley (1954), e The teachings of Don Juan, de Carlos Castanheda (1968), e o interesse acadêmico interdisciplinar nas plantas psicoativas e em suas propriedades visionárias e terapêuticas, que foi marcante entre os anos 1950 e $1970^{3}$.

2 Para maiores informações sobre os usos do peiote entre os Cora e Huichol, ver o capítulo de Maria Benciolini e Arthuro C. del Angel (2016).

3 Para uma abordagem não convencional sobre este tema, ver o capítulo de Erica Dyck, na coletânea, que aborda a história do peiote no Canadá e da Native American Church of Canada (NACC). A autora descreve a interessante aliança estabelecida entre as lideranças deste movimento e as autoridades mundiais nas pesquisas psicodélicas nos anos 1950, buscando legalizar o uso ritual do peiote por parte da NACC no Canadá (Dyck, 2016). 
Entretanto, esse cacto habita o imaginário ocidental desde o início dos tempos coloniais. Assim, longe de terem origem na "guerra às drogas", a perseguição e os preconceitos associados ao peiote já existem há muitos séculos. Esse tema é discutido por Alexander Dawson em um dos capítulos mais interessantes da coletânea, que aborda o peiote no imaginário colonial. Em contraposição à ideia de que a associação entre peiote e indianidade seria "natural", Dawson ressalta as contestações e a instabilidade dos significados atribuídos a esse cacto ao longo do tempo, argumentando que foi necessário um longo processo para transformar o peiote em algo "plenamente indígena". De acordo com este autor, os significados do peiote na sociedade colonial eram múltiplos, uma vez que esta planta era empregada em diversos fins "mundanos" e era particularmente atraente sob a forma de uma "medicina mágica", sendo associada a ideias como curandeirismo e superstição (2016: 52). Assim, conforme as práticas médicas populares e não oficiais foram sendo crescentemente estigmatizadas e perseguidas pela medicina oficial, a associação entre o peiote e ideias como indianidade e "medicina tradicional" tornou-se mais e mais dominante (Dawson, 2016: 60).

Voltando para os processos mais recentes, um dos resultados da popularização do peiote a partir dos anos 1960 e de sua crescente ligação com experiências "espirituais", "místicas" e "xamânicas" foi a expansão dos usos deste cacto. Desse modo, existe hoje uma gama considerável de práticas que envolvem os usos rituais do peiote e que se estendem para além daquelas feitas pelos grupos indígenas e reconhecidas como "tradicionais" (Labate e Feeney, 2016: 214). Dentro desse espectro, encontram-se cerimônias conduzidas por indígenas e direcionadas a não indígenas; tours de peiote e rituais voltados para os turistas que visitam as comunidades próximas de Wirikuta, em San Luis Potosí, México; uma ampla gama de cerimônias espirituais e terapêuticas que combinam elementos da Native American Church (NAC) ${ }^{4}$ com outras tradições, incluindo rituais indígenas mexicanos; e o uso entre grupos indígenas que não eram previamente conhecidos por empregar o peiote (idem).

Essa expansão e diversificação contemporâneas dos usos do peiote apontam uma série de comparações possíveis entre o caso deste cacto e o da bebida de origem amazônica conhecida popularmente como ayahuasca. ${ }^{5}$ Nos dois casos, trata-se de substâncias que se tornaram populares no imaginário ocidental a partir dos anos 1960 e 1970 devido a suas propriedades psicoativas e visionárias e à sua associação com ideias como "espiritualidade", "xamanismo" e "medicina tradicional". Também nos dois casos os usos dessas substâncias vêm se expandindo com o crescimento de redes xamânicas contemporâneas que conectam integrantes de comunidades indígenas, muitas vezes localizadas em lugares considerados remotos e de difícil acesso, a moradores de grandes cidades nas mais diversas partes do mundo. Nessas redes circulam diversos atores, entre os
4 O estabelecimento da Native American Church, que pode ser considerada como a primeira instituição religiosa pan-indígena, constituiu uma estratégia para defender o peiotismo, que se expandiu entre os grupos indígenas norte-americanos no final do século XIX (Soni, 2016). A institucionalização como uma igreja e a incorporação de influências e elementos cristãos, ao lado do uso do peiote como um "sacramento", refletem a busca de apresentar essas práticas como uma religião legítima e organizada que pudesse ser protegida pela legislação norte-americana (idem). De acordo com Varun Soni (2016), a NAC constitui hoje a maior organização religiosa nativa nos Estados Unidos, com cerca de 650 mil participantes.

5 Ver, entre outros, Labate e Araújo (2004); Labate, Rose e Santos (2008). 
quais se incluem: autointitulados "xamãs" e lideranças indígenas; "neoxamãs" e "neonativos"; turistas xamânicos; psiconautas; pessoas ligadas ao universo new age em busca de autoconhecimento, cura ou experiências espirituais; ou simples curiosos ${ }^{6}$. Somado a isso, a expansão dos usos tanto da ayahuasca quanto do peiote vem levantando debates a respeito de temas que incluem políticas nacionais e internacionais de usos e tráfico de drogas, bem como direitos humanos e liberdade religiosa-debates que têm tido diferentes desdobramentos e soluções ${ }^{7}$.

Entretanto, há também diferenças importantes na expansão dos usos da ayahuasca e do peiote. Como indicam Beatriz C. Labate e Kevin Feeney, de maneira distinta do que acontece com relação à ayahuasca, no caso do peiote as novas modalidades de uso ainda são emergentes e aparecem numa escala muito pequena em comparação aos usos definidos como "tradicionais" (2016: 215). Outra diferença fundamental entre esses dois casos reflete-se em um dos temas transversais abordados ao longo da coletânea organizada por Labate e Canvar: o debate ambiental ligado à importância da preservação e da conservação do peiote. Vários capítulos ao longo do livro trazem uma denúncia da diminuição dramática das populações deste cacto ao longo das últimas décadas ${ }^{8}$. As ameaças ao peiote, tanto nos Estados Unidos quanto no México, devem-se a uma série de fatores que englobam: colheitas predatórias e feitas com técnicas inadequadas; aumento no consumo tanto indígena quanto não indígena; tráfico nacional e internacional; mudanças no habitat natural, impactado por grandes projetos agrícolas, de pecuária e de mineração.

Outro aspecto que deve ser levado em conta é o aumento do turismo xamânico na região de Wirikuta, tema discutido no capítulo de Vincent Basset. Com base no seu estudo de caso, Basset indica uma relação entre o turismo xamânico e o processo de revival do xamanismo nativo e de tomada de papel político por parte dos Huichol ou Wixitari (2016: 192). Neste caso específico, essa agência política foi recentemente impulsionada por uma ação do governo mexicano, que garantiu 22 concessões à mineradora canadense First Majestic Silver para a extração de prata dentro da reserva natural sagrada de Wirikuta (2016: 196). Face a essa ameaça, a estratégia desenvolvida pela comunidade wixarica foi a de abrir seus rituais para a participação de não indígenas e procurar levar suas reivindicações para o âmbito internacional com o apoio de acadêmicos, ambientalistas e outros simpatizantes (2016: 206).

O debate ambiental ligado ao peiote aponta a importância e a urgência de pensar em como garantir a sustentabilidade deste cacto no contexto atual de degradação do seu habitat natural e do aumento do consumo, sendo uma das alternativas discutidas no livro o cultivo. Entretanto, o cultivo do peiote atualmente não é oficialmente permitido, tanto nos Estados Unidos quanto
6 Para um debate geral sobre a expansão atual dos xamanismos ligados a ayahuasca, ver Labate e Canvar (2014). Para uma etnografia e estudo de caso sobre a emergência das redes xamânicas contemporâneas no Brasil, ver Rose (2010).

7 Para uma discussão recente sobre o processo de expansão e internacionalização do Santo Daime, incluindo um resumo sobre os debates legais em diversos países europeus e nos Estados Unidos, ver Assis e Labate (2014).

8 Isto vem ocorrendo tanto na área do Texas conhecida como Peyote Gardens (Trout e Terry, 2016) quanto na região de Wirikuta, no deserto de Real de Catorce, em San Luís Potosí (Rojas-Arechiga e Flores, 2016). O peiote é regulamentado internacionalmente por meio da Convenção do Comércio Internacional em Espécies Ameaçadas da Flora e da Fauna Selvagens (CCIEA), que categoriza o cacto como uma espécie em risco de se tornar ameaçada (Labate e Feeney, 2016: 211). Somado a isso, atualmente no México o peiote é classificado como uma planta que precisa de "proteção especial". Já nos Estados Unidos, devido à crescente dificuldade para obter o cacto e à diminuição no tamanho dos botões, a NAC declarou a partir dos anos 1990 a "crise do peiote" (Feeney, 2016: 105) 
no México (Feeney, 2016: 114). Somado a isso, mesmo entre as lideranças da NAC não existe um consenso com relação ao cultivo desta planta (Prue, 2016: 138). Também cabe indicar que há evidentes contradições entre o fato de o peiote ser listado como uma espécie que requer proteção ambiental especial e, ao mesmo tempo, ser classificado como uma droga proibida, o que limita as potenciais estratégias de conservação, incluindo o cultivo, bem como as pesquisas sobre seus potenciais terapêuticos (Labate e Feeney, 2016: 230).

Um segundo tema transversal discutido na coletânea diz respeito às legislações e regulamentações do cacto no México, nos Estados Unidos e no Canadá. Vemos ao longo do volume que, enquanto, por um lado, o peiote é listado em diversas convenções internacionais sobre drogas, de maneira que tanto a planta quanto a mescalina são proibidas, esses países, por outro lado, com base no princípio da liberdade religiosa, têm desenvolvido uma série de mecanismos para proteger seus usos tradicionais entre grupos indígenas (Labate e Feeney, 2016: 211). As isenções legais para usos indígenas religiosos e tradicionais do peiote estão presentes no México e nos Estados Unidos, onde o debate sobre esse tema está ligado à expansão do peiotismo e da Native American Church (NAC), movimento pan-indígena norte-americano criado nas primeiras décadas do século xx. ${ }^{9}$

Desde que foi criada, a NAC vem disputando várias batalhas legais em diversos estados norte-americanos para defender seu direito religioso de consumir essa planta. Uma delas foi o caso Employment Division v. Smith, que aconteceu no estado de Oregon em 1990. Nesse episódio, a decisão da Suprema Corte foi contrária a garantir os direitos trabalhistas dos membros da NAC que foram demitidos pelo uso do peiote. Essa decisão, que implicava em uma redução significativa das garantias constitucionais para a liberdade religiosa, representou uma ameaça para a liberdade não apenas dos praticantes da NAC, mas de todos os grupos religiosos minoritários nos Estados Unidos. Desse modo, o episódio gerou uma ampla mobilização entre diferentes grupos religiosos e civis nos Estados Unidos (Forren, 2016). Um dos desdobramentos desse caso foi a aprovação, em 1993, do Religious Freedom Restoration Act (RFRA), que representou um passo importante na garantia da liberdade religiosa neste país. Somado ao RFRA, a mobilização específica dos membros da NAc também levou à aprovação de uma emenda do American Indian Religious Freedom Act (AIRFA), ato de 1978 que garante a proteção e a preservação da liberdade religiosa e das práticas religiosas nativas ${ }^{10}$.

Por um lado, as isenções para o uso indígena do peiote representam um avanço importante no contexto das políticas proibicionistas e da guerra às drogas. Por outro, há limitações na proposta de restringir o consumo do peiote a indivíduos que possam comprovar sua identidade indígena (Labate e Feeney,
9 Cabe apontar que também no Brasil o debate sobre a regulamentação dos usos do peiote foi recentemente levantado. $O$ tema foi trazido à tona pelas lideranças do Fogo Sagrado de Itzachilatlan, organização espiritual internacional também conhecida como Caminho Vermelho e que se auto-define como uma vertente da NAC. Embora reúnam elementos de uma série de tradições, tanto indígenas quanto não indígenas, a cosmologia e as práticas do Fogo Sagrado são inspiradas principalmente nos grupos indígenas norte-americanos (ver Rose, 2010). Entretanto, devido à proibição do peiote no Brasil, essas práticas vêm sendo realizadas com ayahuaca, bebida cujo consumo é legalizado para fins definidos como rituais e religiosos. Com base neste importante precedente, em 2015 o Conselho Nacional de Políticas sobre Drogas (Conad) constituiu um grupo multidisciplinar de trabalho (GMT) para pesquisar o uso ritual e religioso do peiote no país. Entretanto, devido a conjuntura política atual, essas discussões não foram levadas adiante.

10 A emenda, aprovada em 1994, fala especificamente sobre o uso religioso do peiote, chamando a atenção para o papel que o uso cerimonial deste cacto como um sacramento religioso desempenha para muitos povos indígenas e sua importância para o modo de vida e a perpetuação de suas culturas (Prue, 2016: 136). Essa emenda determina que o uso, a posse ou o transporte do peiote por indígenas que usem o cacto de maneira tradicional e com propósitos cerimoniais e religiosos bona fide não devem ser proibidos (idem). 
2016; Guzmán, 2016). Assim, embora nos Estados Unidos haja uma proteção para o peiotismo indígena, uma série de grupos indígenas é excluída dessa isenção legal devido à falta de reconhecimento de algumas tribos por parte do governo, entre outros motivos (Labate e Feeney, 2016: 214). Já no caso do México, os usos tradicionais feitos pelas populações mestiças são excluídos das proteções legais, bem como os crescentes usos não indígenas ligados ao universo new age, ao neoxamanismo e ao crescimento global do turismo xamânico (Labate e Feeney, 2016: 220). Podemos dizer, portanto, que os usos contemporâneos do peiote têm um caráter transversal e múltiplo. Como argumenta Guzmán, o campo do peiote vai para além de fronteiras étnicas e se expande também para além de fronteiras nacionais, envolvendo grande variedade de participantes em escala local e translocal (2016: 245). Assim, a principal limitação das isenções legais para os usos do peiote definidos como "indígenas" e "tradicionais", tanto nos Estados Unidos quanto no México, é a de que elas não reconhecem os usos populares mestiços ou as cerimônias contemporâneas híbridas (Labate e Feeney, 2016: 220).

Pode-se dizer, portanto, que o peiote situa-se hoje numa espécie de encruzilhada, na qual se encontram debates sobre questões ambientais e de sustentabilidade; políticas nacionais e internacionais que tratam de usos e tráfico de drogas; direitos humanos e indígenas e questões étnicas e religiosas (Labate e Feeney, 2016: 237). Nesse sentido, uma das discussões levantada de diferentes maneiras ao longo do livro diz respeito a como esses diversos interesses interagem e a como eles podem ser devidamente equilibrados (idem).

Isabel Santana de Rose possui graduação em Ciências Sociais com Habilitação em Antropologia pela Unicamp (2002), Mestrado (2005) e Doutorado (2010) em Antropologia Social pela Universidade Federal de Santa Catarina e Pós-Doutorado pelo PPGAS UFSC/INCT Brasil Plural (2010-2012) e pelo PPGAN/UFMG (2014-2016).

\section{REFERÊNCIAS BIBLIOGRÁFICAS}

ASSIS, Glauber L. e LABATE, Beatriz C.

2014 "Dos igarapés da Amazônia para o outro lado do Atlântico: a expansão e internacionalização do Santo Daime no contexto religioso global". Religião e sociedade, 34(2): 11-35. 
BASSET, Vincent

2016 "New Age tourism in Wirikuta: Conflicts and Rituals". In LABATE,

Beatriz C. e CANVAR, Clancy (orgs.), Peyote. History, Tradition, Politics and

Conservation. Santa Barvara/Denver, Praeger, pp. 191-210.

DAWSON, Alexander

2016 "Peyote in the colonial imagination". In LABATE, Beatriz C. e CANVAR, Clancy (orgs.), Peyote. History, Tradition, Politics and Conservation. Santa Barvara/Denver, Praeger, pp. 43-62.

DYCK, Erika

2016 "Peyote and psychedelics on the Canadian praries". In LABATE, Beatriz

C. e CANVAR, Clancy (orgs.), Peyote. History, Tradition, Politics and

Conservation. Santa Barvara/Denver, Praeger, pp. 151-170.

FEENEY, Kevin

2016 "Peyote, conservation and Indian rights in the United States". In LABATE, Beatriz C. e CANVAR, Clancy (orgs.), Peyote. History, Tradition, Politics and Conservation. Santa Barvara/Denver, Praeger, pp. 105-128.

GUZMÁN, Mauricio G.

2016 "Why peyote mus be valued as a biocultural patrimony of Mexico". In LABATE, Beatriz C. e CANVAR, Clancy (orgs.), Peyote. History, Tradition, Politics and Conservation. Santa Barvara/Denver, Praeger, pp. 239-264.

FORREN, John P.

2016 "State and federal legal protections for peyote use in the United States". In LABATE, Beatriz C. e CANVAR, Clancy (orgs.), Peyote. History, Tradition, Politics and Conservation. Santa Barvara/Denver, Praeger, pp. 85-104.

LABATE, Beatriz C.; CANVAR, Clancy; e DAWSON, Alexander 2016 "Introduction-Peyote: past, present and future". In LABATE, Beatriz C. e CANVAR, Clancy (orgs.), Peyote. History, Tradition, Politics and Conservation. Santa Barvara/Denver, Praeger, pp. xVII-Xxv.

LABATE, Beatriz C. e FEENEY, Kevin

2016 "Paradoxes of peyote regulation in Mexico: drug conventions and environmental laws". In LABATE, Beatriz C. e CANVAR, Clancy (orgs.), Peyote. History, Tradition, Politics and Conservation. Santa Barvara/Denver, Praeger, pp. 211-238. 
LABATE, Beatriz C. e CANVAR, Clancy (orgs.)

2014 Ayahuasca Shamanism in the Amazon and Beyond. Oxford, Oxford University Press.

LABATE, Beatriz C. e SENA ARAÚJO, Wladimyr (orgs.)

2004 O uso ritual da ayahuasca ( $2^{\mathrm{a}}$ ed.). Campinas, Mercado de Letras/Fapesp.

LABATE, Beatriz C.; DE ROSE, Isabel S.; E DOS SANTOS, Rafael C.

2008 Religiões ayahuasqueiras: um balanço bibliográfico. Campinas, Mercado de Letras/Fapesp.

PRUE, Bob

2016 "Protecting the peyote for future generations: building on a legacy of perseverance". In LABATE, Beatriz C. e CANVAR, Clancy (orgs.), Peyote. History, Tradition, Politics and Conservation. Santa Barvara/Denver, Praeger, pp. 129-150.

ROJAS-ARÉCHICA, Mariana e Joel Flores

2016 "An overview of catcti and the controversial peyote". In LABATE, Beatriz C. e CANVAR, Clancy (orgs.), Peyote. History, Tradition, Politics and Conservation. Santa Barvara/Denver, Praeger, pp. 21-42.

ROSE, Isabel Santana

2010 Tata endy rekoe - Fogo Sagrado: encontros entre os Cuarani, a ayahuasca e o Caminho Vermelho. Florianópolis, tese, Universidade Federal de Santa Catarina.

SONI, Varun

2016 "Peyote, christianity, and constitutional Law: toward an antisubordination jurisprudence". In LABATE, Beatriz C. e CANVAR, Clancy (orgs.), Peyote. History, Tradition, Politics and Conservation. Santa Barvara/Denver, Praeger, pp. 63-84.

TROUT, Keeper e TERRY, Martin

2016 "Decline of the genus Lophophora in Texas". In LABATE, Beatriz C. e CANVAR, Clancy (orgs.), Peyote. History, Tradition, Politics and Conservation. Santa Barvara/Denver, Praeger, pp. 01-20. 